\title{
"Perceptions of research structures and service quality within various faculties at Durban University of Technology: staff and students perspective"
}

\begin{tabular}{|c|c|c|}
\hline AUTHORS & \multicolumn{2}{|c|}{$\begin{array}{l}\text { Musawenkosi Ngibe (D https://orcid.org/0000-0002-4954-1460 } \\
\text { Lawrence Mpele Lekhanya (D https://orcid.org/0000-0002-9104-963X }\end{array}$} \\
\hline ARTICLE INFO & \multicolumn{2}{|c|}{$\begin{array}{l}\text { Musawenkosi Ngibe and Lawrence Mpele Lekhanya (2016). Perceptions of } \\
\text { research structures and service quality within various faculties at Durban } \\
\text { University of Technology: staff and students perspective. Problems and } \\
\text { Perspectives in Management, 14(1-1), 192-200. doi: 10.21511/ppm.14(1- } \\
\text { 1).2016.07 }\end{array}$} \\
\hline DOI & \multicolumn{2}{|c|}{ http://dx.doi.org/10.21511/ppm.14(1-1).2016.07 } \\
\hline RELEASED ON & \multicolumn{2}{|l|}{ Monday, 11 April 2016} \\
\hline JOURNAL & \multicolumn{2}{|c|}{ "Problems and Perspectives in Management" } \\
\hline FOUNDER & \multicolumn{2}{|c|}{ LLC “Consulting Publishing Company "Business Perspectives" } \\
\hline $0^{\circ}$ & 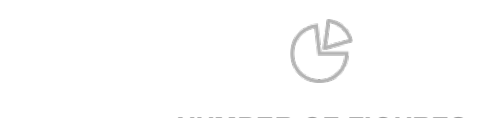 & 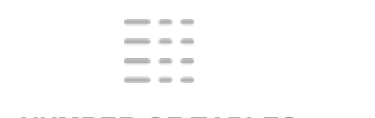 \\
\hline NUMBER OF REFERENCES & NUMBER OF FIGURES & NUMBER OF TABLES \\
\hline 0 & 0 & 0 \\
\hline
\end{tabular}

(c) The author(s) 2023. This publication is an open access article. 
Musawenkosi Ngibe (South Africa), Lawrence Mpele Lekhanya (South Africa)

\title{
Perceptions of research structures and service quality within various faculties at Durban University of Technology: staff and students perspective
}

\begin{abstract}
In order to compete, retain and attract postgraduate students, and overcome the lack of postgraduate throughput, universities of technology need to be more customer orientated. Therefore, to gain competitive advantage, university management needs to identify and assess the service quality gaps in research support structures and analyze the impact they have on students and staff within the university. The purpose of the study is to investigate the perceptions of staff and postgraduate students with regard to research structures and service quality support by relevant offices with specific reference to Durban University of Technology. Data were collected from academic staff and students across six faculties at the Durban University of Technology. The sample consisted of 278 academic staff and 260 postgraduate students, using a simple random sampling. A mixed method approach of qualitative and quantitative techniques was used, with a closed and open-ended questionnaire developed, by adapting the SERVQUAL instrument developed by Parasuraman et al. (1985), to evaluate and assess the quality dimensions (gap) for reliability, responsiveness, assurance and empathy. The findings of the study indicated that staff and students were dissatisfied with the research support structures across six faculties. Further research should aim at assessing performance management of research support structures and service within the relevant research offices.
\end{abstract}

Keywords: perceptions, services, structures, quality, various, research, staff, perspective, faculties, university, technology. JEL Classification: M21.

\section{Introduction}

According to the South African Minister of Higher Education (Nzimande) (2014), South African universities are not producing the right number of masters and doctoral graduates. There is thus a need for universities of technology (UoT) to attract and increase the number of postgraduate students and upgrade their academic staff to the level of postgraduates' qualifications. While this problem is affecting the level of research output and research throughput in the country, these challenges make it likely that they will impact the quality of teaching and learning strategies in the universities, with specific reference to the universities of technology, if not corrected.

\section{Aims and objectives}

1.1. Aim. To analyze and evaluate the overall perception of staff and students, with regard to research structures and service quality support by relevant offices, and the implications thereof.

\subsection{Secondary objective.}

- To identify and examine factors that influence perceptions of staff and students towards faculty research structures and service quality provided by those research offices within the university.

(C) Musawenkosi Ngibe, Lawrence Mpele Lekhanya, 2016.

Musawenkosi Ngibe, Ph.D., Faculty of Accounting and Informatics, Durban University of Technology, South Africa.

Lawrence Mpele Lekhanya, Ph.D., Department of Public Management and Economics, Faculty of Management Science, Durban University of Technology, South Africa.
- To evaluate to what extent these factors influence research output among the university community, with specific reference to academic staff and students.

\section{Literature review}

This section outlines the literature review for gathering the information used to formulate the questionnaire for this survey.

2.1. Research structures at DUT. The Postgraduate Development and Support Centre at DUT was established in 2008 to enhance postgraduate research activities. The centre administers, amongst other, postgraduate scholarships and bursaries, provides financial assistance, promotes research output, tracks postgraduate exchanges and study visits, recruits international postgraduate students, and assists existing staff to upgrade their qualifications (duPre, 2009). Subsequently, due to the demand in postgraduate studies and the ever increasing number of postgraduate student enrolment, the development of Faculty Research offices (FROs) was imminent. When these offices were developed, some of the responsibilities were shifted to them. Each of the six faculties (Accounting and Informatics, Arts and Design, Engineering and Built Environment, Health Sciences and Management Sciences) within the university has a structure that consists of one Research Coordinator and one Faculty Research Officer, with the exception of the faculty of Management Sciences, which has more than two research assistants.

Given the struggling global and South African economies, higher education institutions are dealing 
with decreased revenues. One way for colleges and universities to accomplish this task is to place a renewed focus on meeting or exceeding the expectations and needs of their customers, namely their students (Boyd, 2012). Green and Ramroop (2014) argue that service quality comprises various criteria that are intangible and subjective, and therefore difficult to measure but nonetheless important. However, it must be remembered that service quality is dependent on academic quality, which it can support but not replace or create. Even when universities are persistent in ensuring service delivery and student satisfaction; the academic basis of research services offered by the university cannot be delivered by administrators alone. They have to be decided in a collaborative partnership between educational and disciplinary experts and experienced research administrators (who know about the practicalities of handling student services on a daily basis). However, a major gap today is the need to have well trained administrative staff to help develop and support research (Research-costing practices).

2.2. Research service quality. Quality in higher education is a complex and multifaceted concept and a single appropriate definition of quality is lacking (Voss, Gruber and Szmigin, 2007). Heck and Johnsrud (2000) state that higher education is facing pressure to add value to its activities and the present view for enhancing educational value is to spend effort on continuous service improvement, to focus on stakeholder interest and to increase student satisfaction. This means that quality in higher education can be determined by the extent to which student needs and expectations can be satisfied (Tan and Sei, 2004).

To establish a research culture in UoTs comes with great challenges, since UoTs were traditionally teaching universities without a research culture. Therefore, proper mechanisms need to be considered if UoTs are to attempt to match the powerhouse research universities. According to Wadesango, Maphosa and Moyo (2014), it is of paramount importance for universities to provide academic support that offers a personal and practical approach to academic study, so as to ensure that research, which is appropriate and relevant to the needs of the economy, can be encouraged. Accordingly, one of the key challenges for the higher education sector involves delivery of a high quality of service to satisfy its staff and students thus helping to achieve sustainability in a competitive service environment (DeShields, Kara and Kaynak, 2005). As argued by Reddy (2014), clients (students) normally expect services they receive to be carried out reliably, accurately and effectively, within a good turnaround time. This demonstrates the importance of service quality in gaining a competitive advantage for individual universities, while also highlighting the need to better understand the role that service quality plays in the higher education sector as a whole (Beaumont, 2012). Therefore, to constantly improve quality of research services and education, training at UoTs should be monitored from time to time (Lekhanya, 2014).

2.2.1. Student and staff perceptions towards research. Research in most universities in Africa is hardly coordinated, while there is often considerable variation in approach and even in fulfilment of the requirements for postgraduate research programs (Mutula, 2011). Thus there are many challenges facing postgraduate research, especially in Africa. Wadesango and Machingambi (2011) state that students in UoT found it difficult to pursue their studies, as a result of supervisors being too busy to be effective in their roles; lack of feedback from supervisors due to enormous workloads; limited knowledge and expertise in the field; communication gaps and disagreements about the research project; and supervisors' level of commitment and interest, as well as a lack of communication of information from relevant offices. Moreover, students perceived a lack of clear information to have the greatest impact on their academic experience (Kandiko and Mawer, 2013). The researchers recommend that, to support student expectations and choices, there should be greater transparency of information about services available.

This situation can be better understood in light of the number of postgraduate students in South African universities having doubled over the past 15 years, whilst the number of permanent academic posts has only increased by 40 percent over the same period. This has resulted in academics being increasingly burdened with an unrealistically high number of postgraduate students to supervise, while often lacking experience of supervision roles (CHE, 2009). Moreover, involvement in research activities among academic staff is currently unsatisfactory and many academic staff place little emphasis on research activities, as these do not promise any rewards, in terms of promotion or salary increase (Tahir and Bakar, 2009).

In times of fierce tertiary education competition, where many institutions offer similar products in terms of fees and educational programs, a student service differential can provide an organization with a distinct competitive advantage (Gyamfi, Agyeman and Otoo, 2012). Since severe competition results in little variation of facilities, the quality of student services has been regarded as one of the main 
factors deciding whether or not the institution operates successfully. Sharabi (2010) argues that both the students and their parents are looking for added value for their money and the higher education institutes have to deliver quality that is compatible with students' expectations and needs (Smith, Smith and Clarke, 2007). This means that higher education institutions should begin to focus on providing service delivery to meet or even exceed the expectations of their students (Gruber, Fu8, Voss and Gläser-Zikuda, 2010).

Besides striving for promotion of good student services and facilities, in order to strengthen competitive advantage of an institution and differentiate it from others, advancing the service quality of the institution ensures that students have a positive impression. It therefore becomes important to analyze students' satisfaction in higher education, in addition to which institutions of higher education could greatly benefit from being able to establish a lasting relationship with their students (Alves and Raposo, 2007). Alumni support is underdeveloped in South Africa. Gbadamosi and de Jager (2009) add that continuous improvement of existing standards is necessary for increasing student satisfaction.

\section{Research methodology}

In this study, a mixed method of qualitative and quantitative approaches was utilized to collect primary data from academic staff and postgraduate students from the six campuses, across all faculties at the Durban University of Technology (DUT), namely, Accounting and Informatics, Applied Sciences, Arts and Design, Engineering and Built Environment, Health Sciences and Management Sciences. A combined qualitative and quantitative questionnaire, with closed and open-ended questions was used. The questionnaire was pretested in order to obtain the required information. The sampling frame consisted of academic staff and registered postgraduate students at the above mentioned faculties. A probability sampling method was utilized to select 278 academic staff and 260 postgraduate students.

Questionnaire design: The combined questionnaire was carefully designed to collect information from academic staff and students about key variables that might help explain differences in research structures and services, put in place in the various FROs to administer effective and efficient postgraduate research support. The student's questionnaire was designed using a five point Likert scale and it was adapted to the SERVQUAL instrument developed by Parasuraman et al. (1985). The respondents were requested to choose their preferred choice of response from the list and further make comments on aspects surrounding the issue/s of postgraduate research structures and services. The questionnaire was divided into Section A (academic staff) and Section B (students). Key questions are summarized in Table 1 and the reliability tests in Table 2.

\subsection{Summary of key questions}

Table 1. Summary of key questions

\begin{tabular}{|c|c|}
\hline Research area & Question \\
\hline $\begin{array}{l}\text { Admin service from research } \\
\text { support perspective }\end{array}$ & $\begin{array}{l}\text { Please indicate the services and } \\
\text { support your Faculty Research } \\
\text { Office offers to staff } \\
\text { Response alternatives: } 6 \text { options }\end{array}$ \\
\hline $\begin{array}{l}\text { Research capacity development and } \\
\text { support }\end{array}$ & $\begin{array}{l}\text { Please indicate the services and } \\
\text { support your Faculty Research } \\
\text { Office offers to staff } \\
\text { Response alternatives: } 7 \text { options }\end{array}$ \\
\hline Reliability of the research office & $\begin{array}{l}\text { Ability to perform the promised } \\
\text { services dependably and accurately } \\
\text { Response alternatives: } 5 \text {-point Likert } \\
\text { scale }\end{array}$ \\
\hline Responsiveness & $\begin{array}{l}\text { Willing to help students and provide } \\
\text { prompt service } \\
\text { Response alternatives: 5-point Likert } \\
\text { scale }\end{array}$ \\
\hline Assurance & $\begin{array}{l}\text { Knowledge and courtesy of staff } \\
\text { members and their ability to convey } \\
\text { trust and confidence } \\
\text { Response alternatives: } 5 \text {-point Likert } \\
\text { scale }\end{array}$ \\
\hline Empathy & $\begin{array}{l}\text { Caring individualized attention the } \\
\text { Faculty Research Office provides to } \\
\text { its customers } \\
\text { Response alternatives: } 5 \text {-point Likert } \\
\text { scale }\end{array}$ \\
\hline
\end{tabular}

3.2. Data analysis: The primary data collected from the respondents were coded into the SPSS (23.0 version) computer package. Data captured were double checked to ensure that information captured was error free.

3.3. Frequencies: Frequencies were used to determine the number of responses that each question received and were also used to crosscheck the coding of the data.

3.4. Validity and reliability: The questionnaire was sent to a statistician and colleagues who are experts in research methodology. Based on their feedback and recommendation, some of the questions were changed and rephrased to allow high content validity. Moreover, the questionnaires were piloted to both academic staff and students, to ensure it measured and collected the desired data. Cronbach's Alpha was used to test reliability of the data collected. Due to the structure of the academic questionnaire, it was difficult to test reliability; however, the Cronbach's Alpha for overall student 
perception was .972 . These results indicate that the reliability of the study was acceptable. More detailed information is given in Table 2 below:

Table 2. Reliability scores

\begin{tabular}{|l|c|c|c|}
\hline \multicolumn{1}{|c|}{ Dimension } & Number of items & Expectations & Perceptions \\
\hline Reliability & 4 & .930 & .851 \\
\hline Responsiveness & 19 & .959 & .939 \\
\hline Assurance & 6 & .969 & .936 \\
\hline Empathy & 6 & .950 & .824 \\
\hline Overall & 35 & .978 & .972 \\
\hline
\end{tabular}

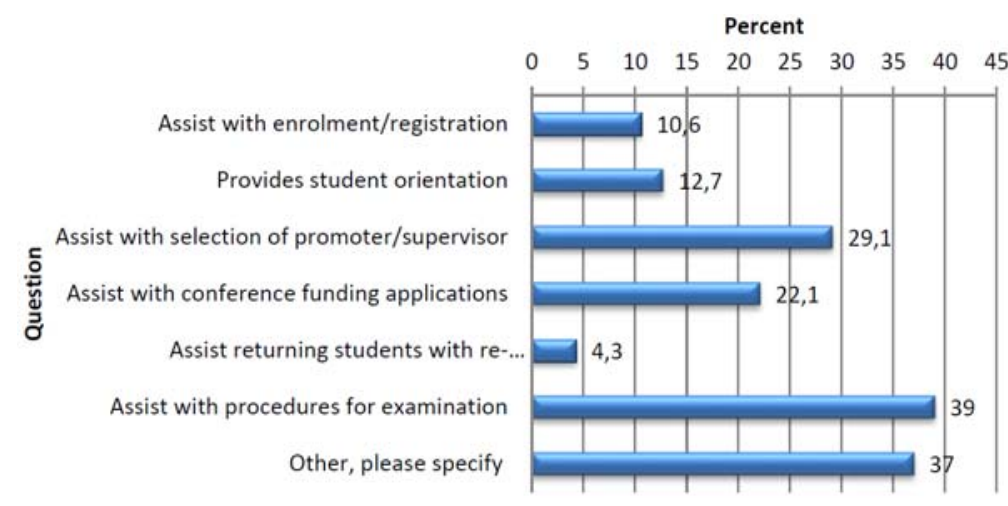

Fig. 1. Sector 1: Administration service and support

A significant minority of the respondents 108 (39 percent) indicated that FROs assisted them with procedures for examination, with 103 (37 percent) of the respondents selecting "other", indicating we were supported by their respective departments when it came to research related activities. On the other hand, qualitative response to this question was the following:

Some academics complained:

- "I only received invites to attend postgraduate induction which were facilitated by the Research and Postgraduate Support Office".

- "No orientation was organized by the FRO to welcome the students to the faculty and give clarity on the faculty procedures and processes, of which they feel it is of great necessity".

- "A Faculty Research Officer should also be placed

\section{Research findings}

4.1. Administration service and support. The administrative service and support provided underpinning any organization is the element that steers the organization in the right direction or when inefficient, can steer it off-course with serious consequences. Staff responses confirmed that FROs do provide research services and support but some were not providing uniformly effective services to their faculties. in Pietermaritzburg Campus to assist us with research as we are uninformed of the services offered to staff members and students".

While 81 (29.1 percent) of the respondents stated they were assisted with selection of promoters/supervisors, 61 (22.1 percent) indicated that they were assisted with conference funding applications. However, only 36 (12.7 percent) indicated that the FRO organizes student orientation for staff and students to better understand the process and services provided to postgraduate students. Only 31 (10.6 percent) of the respondents indicated they were assisted with enrolment/registration, and a small minority 12 (4.3 percent) agreed they were assisted with readmission/continuation of study. This may be due to registration being carried out by the Faculty Office.

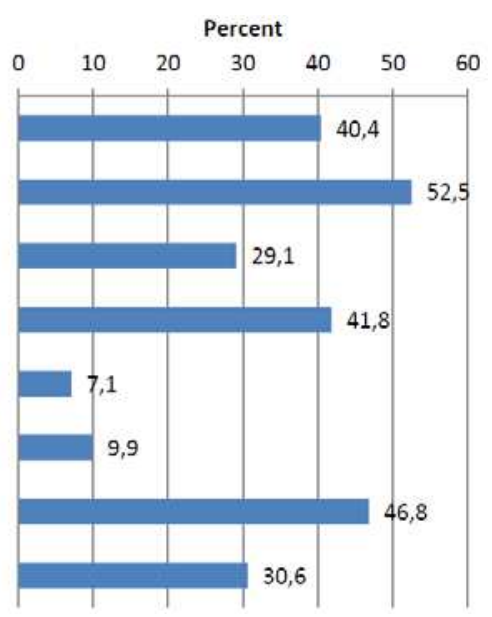

Fig. 2. Sector 2: Research capacity development and support 
The majority of the respondents indicated that their FROs do provide Research Capacity development and support, 112 (30.6 percent) said that the FRO was not assisting them and that they received assistance from their departments and senior lecturers within the department. Of the staff, 147 (52.5 percent) indicated that their FROs were providing assistance in obtaining research ethics clearance and 117 (41.8 percent) stated that specific training sessions were organized on request from staff. With 131 (46.8 percent) indicating that computer labs were available for postgraduate students and 112 (40.4 percent) respondents indicating that they received financial support to have their research published, the initiative to push and encourage postgraduate studies was evidently bearing some fruit.

Through the financial support offered to staff to publish their research, it is expected that an increase in publications will be evident in the coming years, taking into account that a portion of the money earned from the state for research output is allocated to researchers' publication accounts, which is usable for purchasing equipment for research purposes, attending conferences, etc. (Schulze, 2008).

Respondents were also asked to state what system of communication was used to transmit and distribute information regarding postgraduate services offered to them. The majority indicated that they received e-mails from their FROs and some indicated they receive information via emails from the department research assistants. Academics acknowledged the support provided to them, however, they indicated that staff and students' expectations for the improvement of research support structures and services were not gathered.

Academics confirmed that conference attendance reports were requested after attending a conference and in most cases they were requested by the Dean's office and Head of department. The majority of respondents felt the structures and services provided for them suffered from a lack of personnel available within the FROs, to assist the ever-increasing intake of postgraduate students. Less than half of the respondents complained that there was no transparency in handling of documentation and that examination processes tended to be exhausting, with examiners reports taking longer than expected to be received. They also pointed out the need to place someone on the Pietermaritzburg Campus to oversee postgraduate inquiries and provide assistance and support to academics staff enrolled in postgraduate studies.

The descriptive statistics for student responses are illustrated in Figure 3. Discussion on the mean and standard deviation for student respondents will be provided on expectations and perceptions relating to reliability, responsiveness, assurance and empathy quality variables.

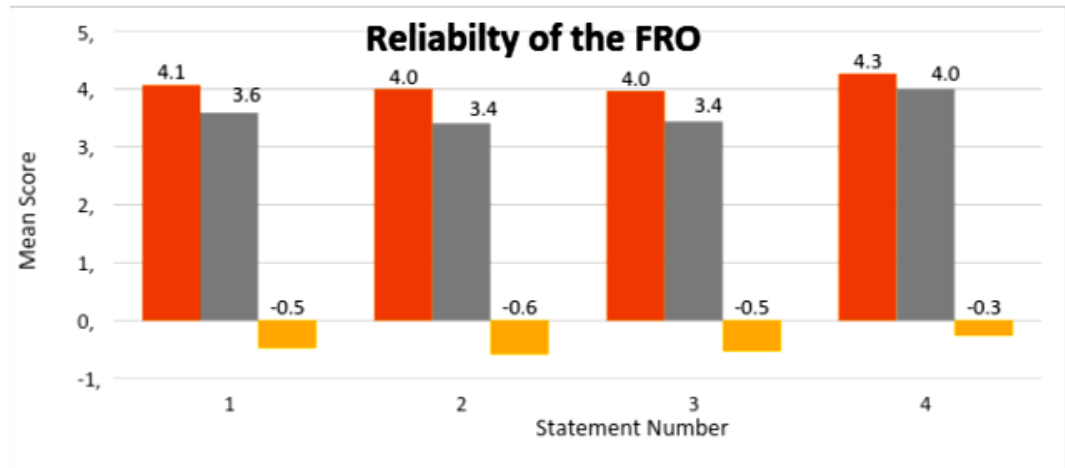

E

Fig. 3. Reliability of the FRO

This presents the findings from four statements on a 5-point Likert scale, regarding the reliability of the FRO at DUT. The overall gap score of -0.5 is similar to the individual gaps. The average expectation and perception scores are similar as well. The expectation scores are high $(\geq 4.0)$ and correspond to (strong) levels of agreement with each. The perception scores average between neutral and the level of agreement (3.4 to 4.0). This consistent level of scoring gives an overall expectation score of 4.1, whilst the perception value is 3.6. These scores indicate that the expectation of service delivery within these areas was higher than the perception. The significance of the difference is tested below. There is an approximate difference of seven percent between the agreement scores for the expectation values between the statements that constitute this dimension. This gap increases to 20 percent for the perception statements. This implies that the respondents mostly had similar views for all of the statements in terms of expectations, but that these views differed in terms of perceptions. This dimension shows that the ability, for the FROs to perform the promised services dependably and accurately, needed improvement. 


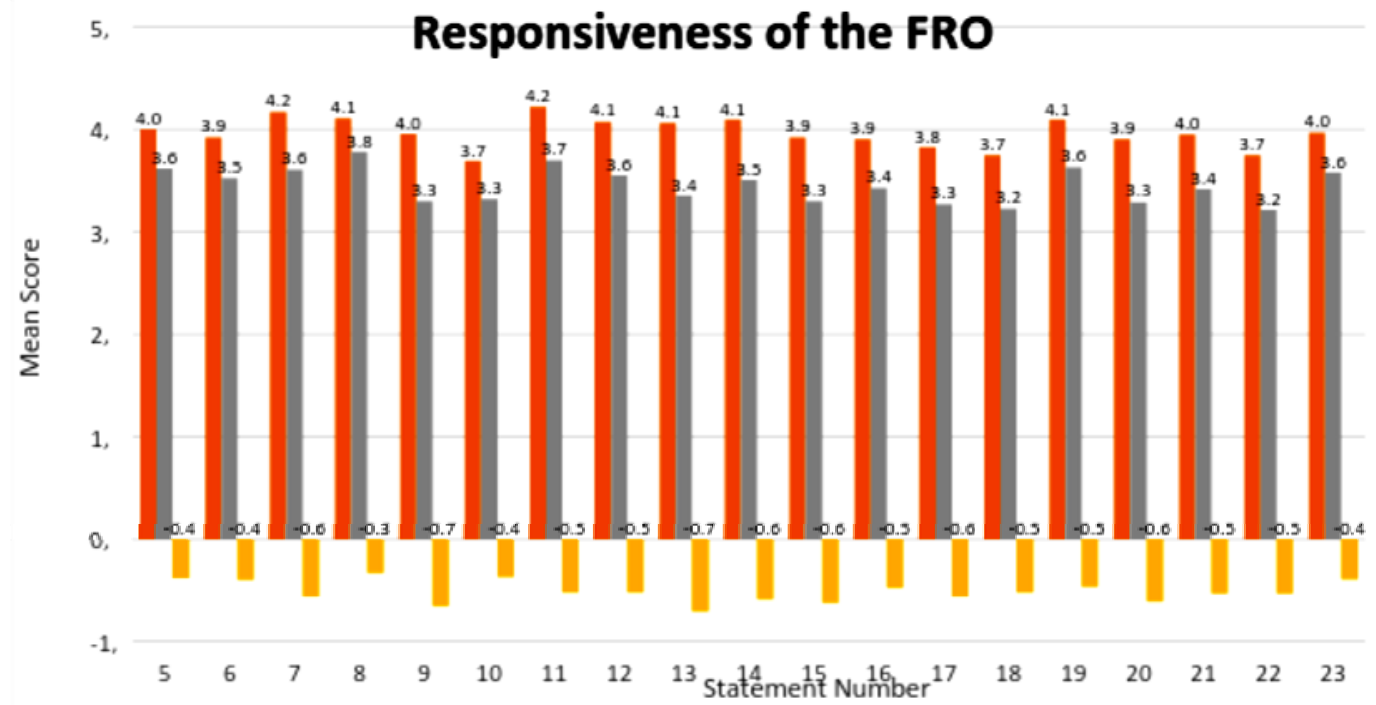

EE EP

Fig. 4. Responsiveness dimension score

This presents the findings from 19 statements on a 5point Likert scale, with regard to the reliability of the FRO at DUT.

The average gap score is -0.5 , with the average Expectation score being 4.0 and the perception score is 3.5. Some gaps are small $(\leq 0.4)$, while some are large. The lowest gap score was -0.3 , based on whether the FRO provided accurate information in terms of postgraduate registration processes. The respondents were slightly less satisfied with the information given to them by the FRO pertaining to $\mathrm{M}$ and DTech registration processes. The response, whether the FRO deals with $\mathrm{M}$ and DTech registration and whether staff always keep students updated about the services they offer, provided the highest gap scores of -0.7 . The respondents mostly agreed that all postgraduate registration processes should be conducted by the FRO, rather than the faculty office, to minimize unnecessary delays. Students expect to be informed of the research services (postgraduate research processes and procedures) provided by FROs, but the resulting gap score indicates that this did not occur sufficiently.

With regards to whether the FROs provide research capacity development and support to postgraduate students, there was a gap score of -0.6. Although the university runs a number of general research workshops, facilitated by experts, to support postgraduate studies; postgraduate students felt they were not receiving sufficient research capacity development and support from their respective FROs, to improve their research capabilities within their respective fields of study.

This section looked at the knowledge and courtesy of FRO staff members and their ability to convey trust and confidence based on six statements.

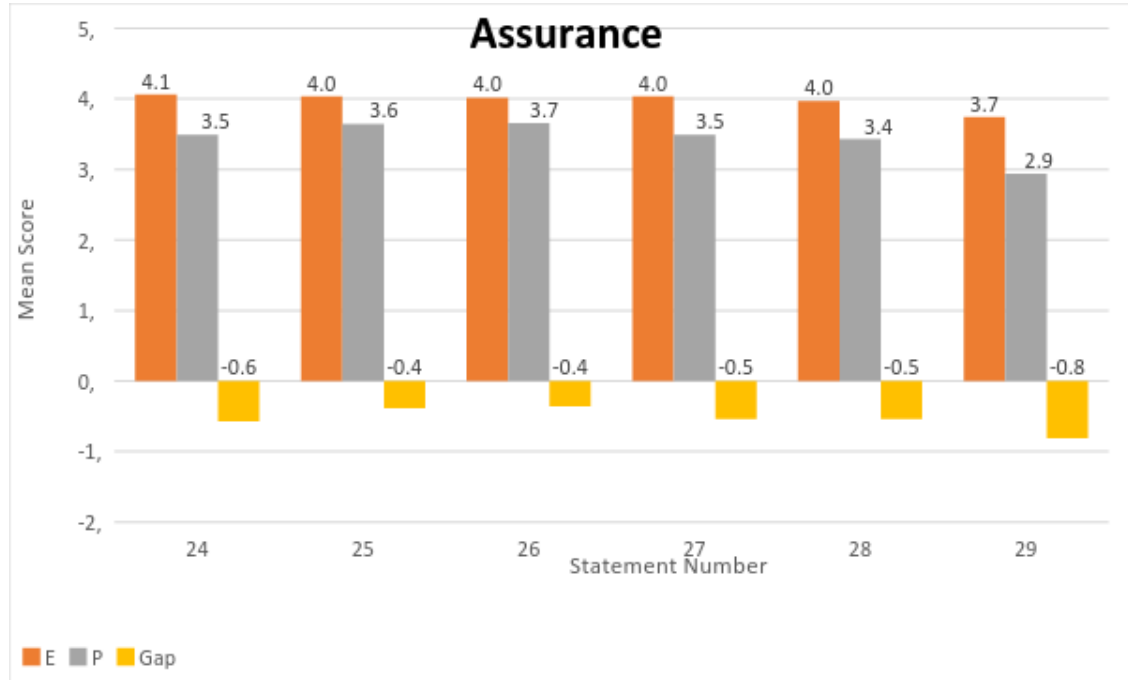

Fig. 5. Assurance dimension score 
This presents the findings from six statements on a 5-point Likert scale, regarding the reliability of the FRO at DUT. The overall gap score of -0.6 is similar to the individual gaps for each statement. The average expectation is 4.0 , while the average perception is 3.4. The expectation scores are high $(\geq 4.0)$ and correspond to (strong) levels of agreement with each of the statements. This indicates that respondents believe the assurance dimension is somewhat lacking. The significance of this difference is tested below.

The lowest gap score was -0.4 , based on whether FRO members had good communication skills (in other words, that they provide clear, helpful, complete and easy-to-understand answers when they attend to students' requests) and whether the FRO staff were eager to assist students. Respondents were not entirely content with the way the FROs communicated, meaning that the information communicated to them was somewhat lacking in quality and not always easy to understand. The gap score of -0.5 indicates that the respondents expected that their queries would be attended to promptly and handled in a manner that would instil confidence was not fully met. Some respondents raised concerns about the lack of transparency in handling research processes.

The largest gap score of -0.8 referred to whether M and DTech students perceived that the FRO was falling short in terms of personnel, and that the FRO structure was not conducive to carrying out the duties and research services it should be providing.

This section discusses the level of caring, individualized attention the FRO provides for its staff and student 'customers'.

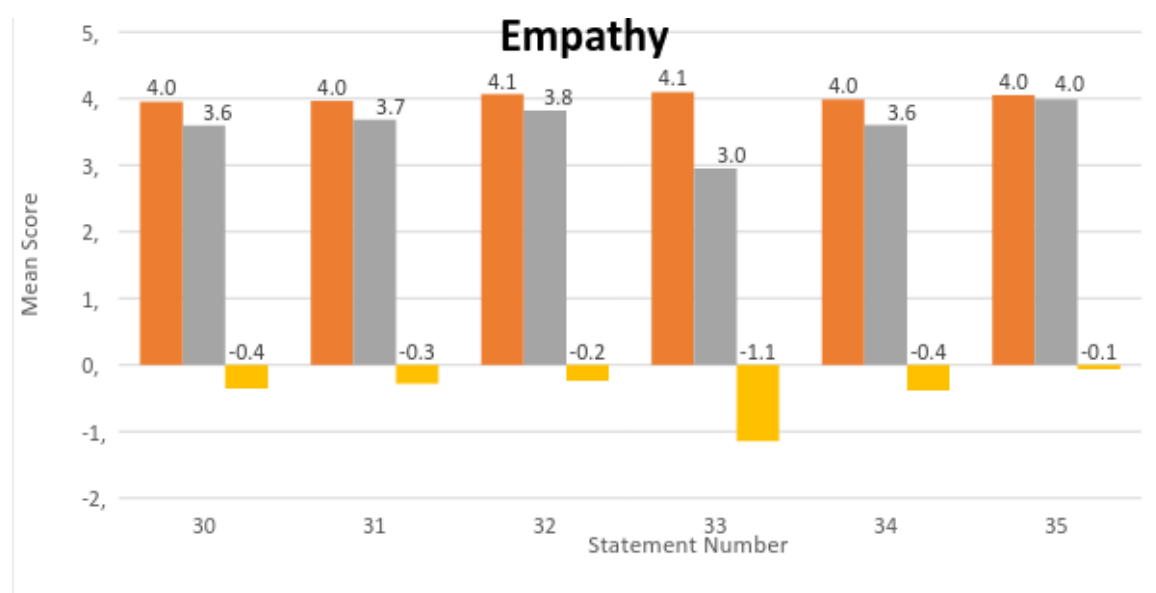

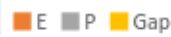

Fig. 6. Empathy dimension score

This presents the findings from six statements on a 5-point Likert scale, with regard to the reliability of the FRO at DUT. The average Gap score is -0.2 , with the average Expectation at 4.0, while the average Perception is 3.6. In this dimension, students perceived that the research services were offered in a reasonably caring manner. The smallest gap score of -0.1 tested whether students perceived the FRO staff to have a neat and professional appearance. In terms of the FRO having convenient operating hours, the students perceived that the FRO had convenient operating hours and that DUT conforms to the working hours set by the South African government and labor law.

Perceptions of research laboratory facilities satisfaction were lower. Due to the ever-increasing intake of postgraduate students, it is important that the university creates more postgraduate laboratories. Students expected (gap score of -0.4) that their faculties would have postgraduate research laboratories with advanced equipment (computer, telephone, printers, etc.). They indicated that the attainment of their expectations in this regard would enable them to focus more on their studies and increase their level of commitment.

The respondents perceived the FRO to be difficult to find and locate. This dimension had the largest gap of -1.1. Realistically, this gap needs to be taken seriously into consideration as it is one of the factors that influences students to seek assistance from their respective departments and supervisors, in preference to the FRO. The researchers strongly believe that, should FROs be situated in more identifiable offices, students might find it easy to associate with their FROs, which could in turn help build a perception of reliability and trust amongst students. At present, FROs are situated in offices that are small and not conducive to consultation.

The overall findings therefore, show that the respondents' perceptions of the four service quality dimensions (reliability, responsiveness, assurance and empathy) were slightly negative, as each of the 
four dimensions had a negative quality gap. The most serious quality problem related to responsiveness and assurance. This indicates that FROs were not seen to be assisting students adequately; that their ability to offer research workshops, willingness to assist students, ability to attend to queries promptly, to provide personnel with expertise in administration, with the ability to look after the best interests of the students adequately, along with their communication of the research services they offer, were all below expectations, to varying degrees. Students were clear that the FRO needed to be prominent in postgraduate activities and also be able to convey a clear and precise understanding of research processes and services to the students.

\section{Recommendations}

The researchers acknowledge the persistent improvement the university has made and that decentralizing of Research Offices was one of those improvements in ensuring the university becomes research orientated. In order to minimize the quality gaps, the researchers argue that the FROs must establish the exact needs of the staff and $\mathrm{M}$ and DTech students within their faculties, so as to be able to organize and provide the required research assistance. The researchers believe that, should research services not be communicated and provided adequately to postgraduate students, it may also be a contributory factor to postgraduate throughput and dropout rates.

It must be noted that, in order to move the university to the next level in terms of postgraduate enrolment, qualification upgrade, and academic publications, the university not only needs to acquire the services of well-established researchers and professors to improve publication rates and to provide good supervision, but also to look at increasing the number of research-driven administrators who strive for service delivery excellence, to cope with the ever-increasing number of enrolled postgraduate students. It should also be highlighted that, in order to achieve the university's objectives, in regard to increased postgraduate enrolment, improved pass rates and scholarly publications, the university needs to focus on FRO processes and procedures for administering research services and try to find a uniform approach that will be adopted by the whole university, so as to minimize the existing gaps.

\section{Conclusions}

The conclusion of this study is based on the key findings. Furthermore conclusions also cover the aim and objectives of the survey. This study concludes that administration services and research capacity development are the major concern for both staff and students. It was also concluded that identified gaps were a concern in the sustainability of research as it was vital for the university to have the ability to provide quality research services as they played a significant role in the success or attraction of postgraduate students; hence these entwined gaps need to be addressed to avoid unnecessary dropouts that have a negative impact on research throughput. It was also concluded that, for efficient and effective research activities, there was a significant need for strong research support structures to cater and administer all research related activities in universities of technology. All these findings were followed to address and attain research aims and objectives. The study concludes that all set objectives were achieved.

\section{References}

1. Alves, H. and Raposo, M. (2007). The influence of university image in student's expectation, satisfaction and loyalty. 29th Annual EAIR Forum. 26-29 August. Innosbruck, Australia.

2. Beaumont, D.J. (2012). Management Service Quality in Higher Education: The students' viewpoint. Unpublished Master's dissertation; Department of Management. Business School. University of Manchester.

3. Boyd, R.L. (2012). Customer service in Higher Education: Finding a middle ground. [Online]. Available at: http://www.dus.psu.edu/mentor/2012/06/customer-service-in-higher-education/. Accessed 10/2/2013.

4. CHE. (2009). Postgraduate Studies in South Africa: A Statistical Profile. Available at: http://www.che.ac.za/sites/default/files/publications/CHE_MonitorProjectV7.pdf. Accessed 10/05/2014.

5. DeShields, Jr. O.W., Kara, A. and Kaynak, E. (2005). Determinants of business student satisfaction and retention in higher education: Applying Herzberg's two-factor theory, International Journal of Educational Management, 19 (2), pp. 128-139.

6. duPre, R. (2009). DUT strategic goals and objectives for 2009 to 2018 and strategic directions 2008-2012. Durban: Division of Corporate Affairs of DUT.

7. Gbadamosi, G. and de Jager, J. (2009). "What you see is what you get": Service quality, students' perceptions and satisfaction at South African universities, South African Journal of Higher Education, 23 (5), pp. 877-893.

8. Green, P. and Ramroop, S. (2014). Prioritising factors influencing service quality at Durban University of Technology: AHP Approach, Journal of Social Science, 40 (20), pp. 243-250.

9. Gyamfi, D.A., Agyeman, A. and Otoo, A.K. (2012). Assessing the provision of quality students' service and satisfaction in tertiary institution in Ghana: Using Cape Coast Polytechnic as Case Study, Asian Journal of Business and Management Sciences, 1 (12), pp. 20-32. 
10. Gruber, T., Fu8, S., Voss, R. and Gläser-Zikuda, M. (2010). Examining student satisfaction with higher education services: Using a new measurement tool, International Journal of Public Sector Management, 23 (2), pp. $105-123$.

11. Heck, R.H. and Johnsrud, L.K. (2000). Administrative effectiveness in higher education: improving assessment procedures, Research in Higher Education, 41 (6), pp. 663-685.

12. Kandiko, C.B. and Mawer, M. (2013). Student expectations and perceptions of Higher Education: Executive Summary. London: King's Learning Institute.

13. Lekhanya, L.M. (2014). Customer service orientation of institutes of higher learning in South Africa: A case study of universities of technology, Corporate Ownership and Control, 11 (4), pp. 299-310.

14. Mutula, S.M. (2011). Challenges of postgraduate research: case of developing countries, South African Journal of Library and Information Science, 77 (1), pp. 184-190.

15. Parasuraman, A., Berry, L.L. and Zeithaml, V.A. (1988). SERVQUAL: A multiple-item scale for measuring consumer perceptions of service quality, Journal of Retailing, 64, pp. 12-40.

16. Reddy, N. (2014). Perceptions and expectations of IT service delivery Post Migration to a Microsoft Platform at a university of technology in South Africa. Unpublished master's dissertation, Department of Information Technology, Faculty of Accounting and Informatics, Durban University of Technology. South Africa.

17. Schulze, S. (2008). Academic research at a South African higher education institution: Quality issues, South African Journal of Higher Education, 22 (3), pp. 644-661.

18. Sharabi, M. (2010). HR manager leadership in quality improvement in a college environment, Quality Assurance in Education, 18 (4), pp. 317-327.

19. Smith, G., Smith, A. and Clarke, A. (2007). Evaluating service quality in universities: a service department perspective, Quality Assurance in Education, 15 (3), pp. 334-351.

20. Tahir, I.M. and Bakar, N.M.A. (2009). An evaluation of lecturers' perceptions towards research, The Social Sciences, 4 (5), pp. 416-423.

21. Tan, K.C. and Sei, W.K. (2004). Service quality in higher education using enhanced SERVQUAL approach, Quality in Higher Education, 10 (1), pp. 17-24.

22. Voss, R., Gruber, T. and Szimigin, I. (2007). Service quality in higher education: The role of student expectations, Journal of Business Research, 60, pp. 949-959.

23. Wadesango, N. and Machingambi, S. (2011). Post graduate students' experiences with research supervisors, The Journal of Sociology and Social Anthropology, 2 (1), pp. 31-37.

24. Wadesango, N., Maphosa, C. and Moyo, G. (2014). An Academic Development Agenda for Postgraduate Research Students, Mediterranean Journal of Social Sciences, 5 (11), pp. 49-56. 